\title{
Chemical elements migration in water-travertin system (Tomsk region, Russia)
}

\author{
Olesya Lepokurova ${ }^{1,2, *}$ \\ ${ }^{1}$ Tomsk Branch of Trofimuk Institute of Petroleum-Gas Geology and Geophysics of SB \\ RAS, 4, Academichesky Ave., Tomsk 634055, Russia \\ ${ }^{2}$ National Research Tomsk Polytechnic University, Lenin Avenue, 30, Tomsk 634050, \\ Russia
}

\begin{abstract}
To assess the mobility of chemical elements in carbonate, formation processes have calculated the water migration coefficient $-K_{x}$ and the geochemical mobility coefficient $-K_{n}$. The series of geochemical mobility were constructed. The elements that can be deposited and that can be accumulated in water have been distinguished. It is shown that anionic elements - $\mathrm{Cl}, \mathrm{S}, \mathrm{Br}, \mathrm{I}, \mathrm{U}$, As, as well as elements such as $\mathrm{Na}, \mathrm{Mg}, \mathrm{Mo}, \mathrm{Zr}$ well pass into solution from rocks and remain in the water. Elements such as $\mathrm{Ca}, \mathrm{Fe}, \mathrm{Al}, \mathrm{Mn}, \mathrm{Si}, \mathrm{Ba}, \mathrm{Zn}, \mathrm{Pb}, \mathrm{Co}, \mathrm{Hg}, \mathrm{Ti}, \mathrm{La}, \mathrm{Ag}, \mathrm{Sn}, \mathrm{Cr}$ are most fully deposited in travertines.
\end{abstract}

\section{Introduction}

Travertines are calcareous tuffs of chemogenic origin formed in the places of groundwater discharge. They are considered the satellites of cold or thermal carbonic waters, which are associated with manifestations of recent volcanism. However, in the south of Western Siberia, which is marked as a zone of passive tectonic activity, travertines widely form from ordinary cold fresh water with carbon dioxide background value. Within the Kolyvan-Tomsk folded area and Salair ridge, more than 120 travertine sites were identified. Such scientists as P.A. Udodov, V.M. Matusevich, S.L. Schvartcev, N.V. Grigoriev, Y.G. Kopylova, E.M. Dutova and many others made a great contribution to the research of waters forming travertines in the study region. In the previous works the author described in detail the mechanism of such carbonate formation [1].In this particular paper the features of component redistribution in the water-travertine system, based on an example from the southern part of the Tomsk region, are considered.

\section{Research object and methods}

The objects of the research are springs constituting travertines in the Basandayka and Tugoyakovka basins (the right tributaries of the Tom River) (Fig. 1) in the northern part of the Kolyvan-Tomsk folded zone.

*Corresponding author: LepokurovaOY @ipgg.sbras.ru 
These are waters of the fault zones of the Paleozoic basement (Devonian-Carboniferous shales), circulating at depths of 100-200 m. On the water exit to the surface carbonate tuffs are generated in the form of baths, cascades, covers and low-power raids (Fig. 1).
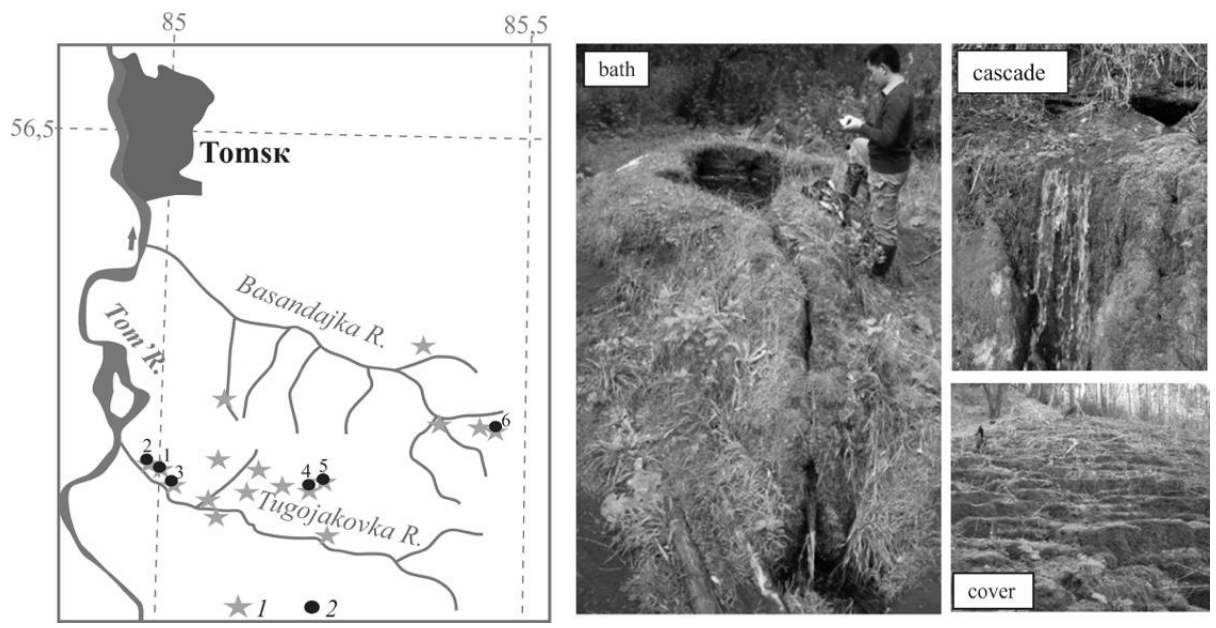

Fig. 1. Scheme of travertine sites (1), pictures of their major occurrences and the sampling sites of water and travertines (2).

Precipitated carbonates are pseudomorphs of vegetal debris and mosses. These are strong and porous rocks in greyish and brownish shades. Studying the rock thin sections helped to determine that travertines are composed mostly (60-80\%) of calcite - aragonite material interstritified with a large amount of clay material. The study also reported the presence of iron hydroxide films - limonite (up to 15\%) and fine-dispersed colloform formations of manganese water oxide - bernessite (up to 10\%) [1].

Waters constituting travertines are cold $\left(4-14^{\circ} \mathrm{C}\right.$ during the summer period), fresh $(0.4-$ $1.1 \mathrm{~g} / \mathrm{L}$ ), neutral or slightly alkaline ( $\mathrm{pH} 7.2-8.4)$ and mainly $\mathrm{HCO}_{3}-\mathrm{Ca}-\mathrm{Mg}$ composition. Content of free $\mathrm{CO}_{2}$ is $118 \mathrm{mg} / \mathrm{L}$. The composition of water-dissolved gases is nitrogenoxygen-carbonic and according to its genesis - atmospheric.

To assess the mobility of chemical elements in carbonate formation processes the author used the water migration coefficient $-K_{x}$ (according to A.I. Perelman) [2] and the geochemical mobility coefficient $-K_{n}$ (according to S.L. Shvartsev) [3].

The first is determined using the following formula:

$K_{x}=\left(m_{x} * 100\right) /\left(a * n_{x}\right) \quad(1)$

where $a$ is the amount of mineral substances dissolved in the water, $\mathrm{mg} / \mathrm{L} ; \mathrm{m}_{\mathrm{x}}$ is the content of the same element $\mathrm{x}$ in the water, $\mathrm{mg} / \mathrm{L} ; n_{x}$ is the content of the same element in rocks, $\%$.

The geochemical mobility coefficient $K_{n}$ is determined by the following formula:

$K_{n}=\left(m_{x} * 100\right) /\left(a * n_{n}\right) \quad(2)$,

where $m_{x}$ and $a$ are the same as in the equation (1); $n_{n}$ is the content (\%) of the tested element in chemical weathering productsor their analogues (soils, peat, precipitated hydroxides, carbonates, etc.).

The calculations are based on data of spectral and neutron activation analyses of travertines and microcomponent composition of waters, performed by the geochemical laboratory of Tomsk Polytechnic University. In total, 20 water and six travertine samples were selected and analysed. The coefficients are calculated to the averages. 


\section{Experimental data}

The coefficient of water migration characterises the conditional speed of chemical elements carrying relative to the abundance in the Earth's crust. The more $K_{x}$, the faster the element leaching. The average values are presented in table 1.

Table 1.Mobility of chemical elements in carbonate formation processes.

\begin{tabular}{|c|c|c|c|c|c|}
\hline element & $K_{x}$ & $K_{n}$ & element & $K_{x}$ & $K_{n}$ \\
\hline $\mathrm{Cl}$ & 1111 & 133 & $\mathrm{Ag}$ & 0,7 & 0,2 \\
\hline $\mathrm{Hg}$ & 50 & 0,004 & $\mathrm{Cr}$ & 0,6 & 0,2 \\
\hline $\mathrm{U}$ & 29,4 & 22,4 & $\mathrm{Ni}$ & 0,3 & 1,5 \\
\hline $\mathrm{Br}$ & 29,2 & 3,7 & $\mathrm{La}$ & 0,3 & 0,2 \\
\hline $\mathrm{As}$ & 22,7 & 1,9 & $\mathrm{Ce}$ & 0,2 & 0,8 \\
\hline $\mathrm{S}$ & 20,0 & 8,3 & $\mathrm{Ba}$ & 0,2 & 0,4 \\
\hline $\mathrm{Mo}$ & 12,5 & 5,0 & $\mathrm{~Pb}$ & 0,2 & 0,3 \\
\hline $\mathrm{Ca}$ & 6,9 & 0,5 & $\mathrm{~B}$ & 0,1 & 6,2 \\
\hline $\mathrm{Sr}$ & 4,4 & 2,2 & $\mathrm{Cr}$ & 0,1 & 0,2 \\
\hline $\mathrm{Zr}$ & 3,7 & 70,0 & $\mathrm{~K}$ & 0,1 & 5,0 \\
\hline $\mathrm{Na}$ & 3,0 & 5,4 & $\mathrm{Co}$ & 0,05 & 0,01 \\
\hline $\mathrm{I}$ & 2,5 & 5,0 & $\mathrm{Si}$ & 0,05 & 0,48 \\
\hline $\mathrm{Sn}$ & 2,4 & 0,2 & $\mathrm{Mn}$ & 0,03 & 0,01 \\
\hline $\mathrm{Mg}$ & 2,4 & 7,8 & $\mathrm{Fe}$ & 0,02 & 0,05 \\
\hline $\mathrm{Zn}$ & 1,2 & 0,3 & $\mathrm{Al}$ & 0,005 & 0,050 \\
\hline $\mathrm{Cu}$ & 0,9 & 0,6 & $\mathrm{Ti}$ & 0,0001 & 0,0004 \\
\hline
\end{tabular}

According to $\mathrm{Kx}$ values, the intensity series of the chemical element removal from the crust of weathering was compiled using the method of A.I. Perelman and B. B. Polynova [4] (Table 2). Cl, Hg, U, Br, As, S, Mo, then Ca, Sr, Zr, Na, I, Sn, Mg, Zn, etc. are well removed from rocks into water. Due to the results of these calculations, $\mathrm{Co}, \mathrm{Si}, \mathrm{Mn}, \mathrm{Fe}, \mathrm{Al}$, and $\mathrm{Ti}$ are removed worse.

Table 2.The series of migration in carbonate formation processes.

\begin{tabular}{|c|c|c|}
\hline intensity of mobility & $K_{x}$ & element \\
\hline very strong & $>10$ & $\mathrm{Cl}, \mathrm{Hg}, \mathrm{U}, \mathrm{Br}, \mathrm{As}, \mathrm{S}, \mathrm{Mo}$ \\
\hline strong & $1-10$ & $\mathrm{Ca}, \mathrm{Sr}, \mathrm{Zr}, \mathrm{Na}, \mathrm{I}, \mathrm{Sn}, \mathrm{Mg}, \mathrm{Zn}$ \\
\hline medium & $0,1-1$ & $\mathrm{Cu}, \mathrm{Ag}, \mathrm{Cr}, \mathrm{Ni}, \mathrm{La}, \mathrm{Ce}, \mathrm{Ba}, \mathrm{Pb}, \mathrm{B}, \mathrm{Cr}, \mathrm{K}$ \\
\hline weakly moving & $<0,1$ & $\mathrm{Co}, \mathrm{Si}, \mathrm{Mn}, \mathrm{Fe}, \mathrm{Al}, \mathrm{Ti}$ \\
\hline
\end{tabular}

However, to fully assess the mobility of any element, it is necessary to determine not only which rocks are chemically destroyed and how much of this element is in solutions, but also which secondary products are formed and the concentration of this element in them. The above classification does not allow an estimation of how many elements can be leached together with secondary products. It is reflected by the coefficient of geochemical mobility $K_{n}$-the ability to concentrate in solution relative to its total salinity and fraction, bound by secondary products (travertines). The results are presented in Table 1, and as can be seen, the $K_{n}$ values differ from $K_{x}$. The series of geochemical mobility was constructed in accordance with the calculated coefficients (Table 3 ). 
Table 3.The series of geochemical mobility in carbonate formation processes.

\begin{tabular}{|c|c|c|}
\hline intensity of mobility & $K_{n}$ & element \\
\hline very strong & $>10$ & $\mathrm{Cl}, \mathrm{Zr}, \mathrm{U}$ \\
\hline strong & $1-10$ & $\mathrm{~S}, \mathrm{Mg}, \mathrm{B}, \mathrm{Na}, \mathrm{K}, \mathrm{Mo}, \mathrm{I}, \mathrm{Br}, \mathrm{Sr}, \mathrm{As}, \mathrm{Cr}, \mathrm{Ni}$ \\
\hline medium & $0,1-1$ & $\mathrm{Ce}, \mathrm{Cu}, \mathrm{Si}, \mathrm{Ca}, \mathrm{Ba}, \mathrm{Zn}, \mathrm{Pb}, \mathrm{La}, \mathrm{Ag}, \mathrm{Sn}, \mathrm{Cr}$ \\
\hline weakly moving & $<0,1$ & $\mathrm{Fe}, \mathrm{Al}, \mathrm{Mn}, \mathrm{Co}, \mathrm{Hg}, \mathrm{Ti}$ \\
\hline
\end{tabular}

Analysing this table, the elements can be seen to migrate well in waters considering travertine binding such as $\mathrm{Cl}, \mathrm{Zr}, \mathrm{U}, \mathrm{S}, \mathrm{Mg}, \mathrm{B}, \mathrm{Na}, \mathrm{K}, \mathrm{Mo}, \mathrm{I}, \mathrm{Br}, \mathrm{Sr}, \mathrm{As}, \mathrm{Cr}$ and Ni. Such elements as $\mathrm{Fe}, \mathrm{Al}, \mathrm{Mn}, \mathrm{Co}, \mathrm{Hg}$, and $\mathrm{Ti}$ migrate poorly in waters. However, in this classification we do not take into account the composition of the original (primary) rocks, which is explained by the author as follows: "... the rock acts as an sustainable source of the element which content remains unchanged in the dissolved rock ...” [3, p.273].

\section{Results and discussion}

The joint manifestation of chemical element migration (transition of elements from rocks into solution and their removal from solutions to travertines)can be represented in the three pillars of the system: source rock - water - secondary sediments (Table 4).

Table 4. Source rocks- water - travertin system.

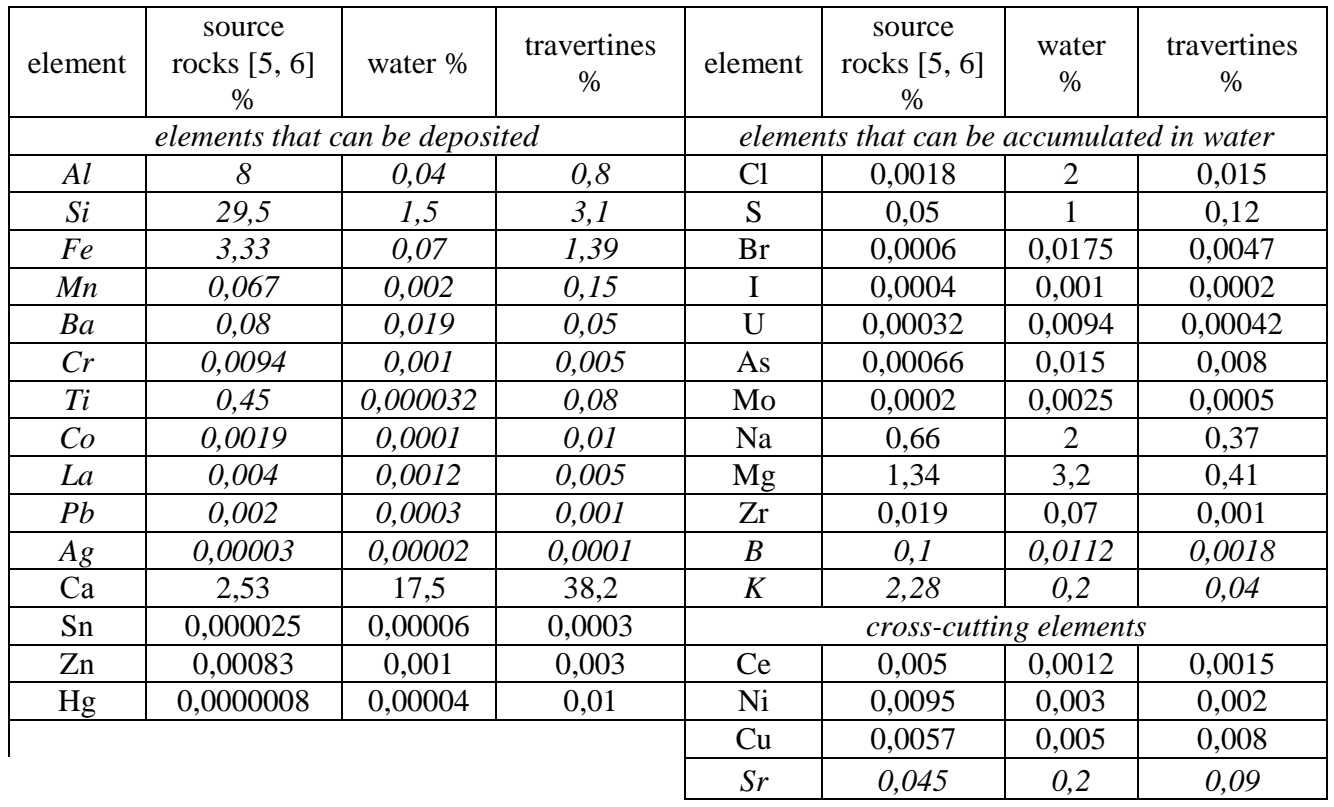

In addition, we conventionally distinguished three groups of elements:1) elements that can be deposited, i.e. there is more of them in deposited travertines than in waters; 2) elements that can be accumulated in water, i.e. there is more of them in water than in travertines; and 3) cross-cutting elements, i.e. with almost equal element contents in water and in travertines. These groups of elements can also be divided into well and poorly capable of carring in reference to the source rocks.

Such elements (elements that can be deposited) as $\mathrm{Ca}, \mathrm{Fe}, \mathrm{Al}, \mathrm{Mn}, \mathrm{Si}, \mathrm{Ba}, \mathrm{Zn}, \mathrm{Pb}, \mathrm{Co}$, $\mathrm{Hg}, \mathrm{Ti}, \mathrm{La}, \mathrm{Ag}, \mathrm{Sn}$ and $\mathrm{Cr}$ are most fully deposited in travertines regarding to the observed geological data. For example, in the study of thin sections it was found that in addition to 
carbonate material, clay minerals, bernessite and limonite were also detected. Such elements as $\mathrm{Al}, \mathrm{Si}, \mathrm{Fe}, \mathrm{Mn}, \mathrm{Ba}, \mathrm{Cr}, \mathrm{Ti}, \mathrm{Co}, \mathrm{La}, \mathrm{Pb}$ and $\mathrm{Ag}$ have the lowest mobility among these elements, taking into account their poor excretion of bedrocks $(K x)$. And such elements as $\mathrm{Ca}, \mathrm{Hg}, \mathrm{Zn}$ and $\mathrm{Sn}$ are well excreted from aluminosilicate rocks into the water, but immediately settle with carbonates.

Cross-cutting elements $(\mathrm{Ce}, \mathrm{Ni}, \mathrm{Cu}, \mathrm{Sr})$ are an interesting group of elements characterised by the same concentrations not only in waters and travertines, but also in the source rocks.

First of all, anionic elements - $\mathrm{Cl}, \mathrm{S}, \mathrm{Br}, \mathrm{I}, \mathrm{U}$ and As as well as elements such as Mo, $\mathrm{Na}, \mathrm{Mg}$ and $\mathrm{Zr}$ pass well into solution from rocks and stay in the water under these conditions. At the same time, they are poorly bound by travertines favouring their migration in the waters. Elements such as B and $\mathrm{K}$ are poorly removed in regards to bedrock and are well concentrated in the waters without binding to secondary deposits.

Thus, these waters are not favourable for migration of $\mathrm{Al}$ and $\mathrm{Si}$ and some metals (Ca, $\mathrm{Fe}$ and $\mathrm{Mn}$ )which are deposited in the form of poorly soluble hydroxides, clay and carbonates. The exceptions are $\mathrm{Na}, \mathrm{Mg}$ and $\mathrm{K}$, which are not in equilibrium at this stage (except for the part of clays)and continue to concentrate. The investigated waters are at the initial stage of soda formation when calcium (and then magnesium, when equilibrium with dolomite occurs) stops rising and sodium, on the contrary, starts to rise sharply. The $\mathrm{HCO}_{3}$ $\mathrm{Na}$ water type lies deeper throughout the region.

When forming its structure, the secondary mineral and organic-mineral phases capture some of the scattered elements, which do not form their own secondary minerals or sorb them on their surface.

\section{Conclusion}

Thus, after studying the chemical element migration within the groundwater system travertines in the basins of the Tugoyakovka and Basandaika rivers(south of Tomsk region) using data on the composition of waters and travertines, water migration coefficient $K_{x}$ and geochemical mobility coefficient $K_{n}$ were calculated. The latter allows the establishing of more objective features of migration behaviour, Since it not only compares chemical elements relative to each other, but also takes into account the banding of the ratio of elements by travertines.

Judging by intensity of mobility, the following elements are identified: very strong $(\mathrm{Cl}$, $\mathrm{Zr}$, U), strong ( $\mathrm{S}, \mathrm{Mg}, \mathrm{B}, \mathrm{Na}, \mathrm{K}, \mathrm{Mo}, \mathrm{I}, \mathrm{Br}, \mathrm{Sr}, \mathrm{As}, \mathrm{Cr}, \mathrm{Ni}$ ), medium (Ce, Cu, Si, $\mathrm{Ca}, \mathrm{Ba}, \mathrm{Zn}$, $\mathrm{Pb}, \mathrm{La}, \mathrm{Ag}, \mathrm{Sn}, \mathrm{Cr}$ ) and weakly moving (Fe, Al, Mn, Co, Hg, Ti).

In general, it is possible to identify such elements as (Ca, Fe, Al, Mn, $\mathrm{Si}, \mathrm{Ba}, \mathrm{Zn}, \mathrm{Pb}$, $\mathrm{Co}, \mathrm{Hg}, \mathrm{Ti}, \mathrm{La}, \mathrm{Ag}, \mathrm{Sn}, \mathrm{Cr}$ ), which are capable of travertine deposition and elements show a marked tendency to accumulate in water. The latter includes anionic elements $(\mathrm{Cl}, \mathrm{S}, \mathrm{Br}, \mathrm{I}$, $\mathrm{U}, \mathrm{As})$, as well as $\mathrm{Na}, \mathrm{Mg}, \mathrm{Mo}, \mathrm{Zr}$.

The author thanks Professor Yulia G. Kopylova for her contribution in the publication of this paper. The research was supported by the Russian Foundation for Basic Research, project No.17-05-00042.

\section{References}

1. S.L. Shvartsev, O.E. Lepokurova, Yu.G.Kopylova, Russian Geology and Geophysics, 48 (8), 659-667(2007)

2. A.I. Perel'man, Geochemistry of nature water[in Russian], 152 (1982)

3. S.L. Shvartsev, Hydrogeochemistry of hypergenesis zone[in Russian], 367 (1998) 
4. B.B. Polynov Landscape geochemistry[in Russian], 751 (1956)

5. A.P. Vinogradov, Geochemistry [in Russian], 7, 555-571 (1962)

6. E.V. Sklyarov, D.P. Gladkochub, T.V. Donskaya, Interpretation of geochemical data [in Russian], 288 (2001) 